\title{
Dynamic Pricing of Perishable Products with Hybrid Consumer Buying Behavior
}

\author{
Weiwei Ji*, Xiaofan Xie, Yinghui Xiao \\ The Department of Basic Course Education, Ji'an College, Ji'an, China \\ Email: *jiweiwei0828@126.com
}

How to cite this paper: Ji, W.W., Xie, X.F. and Xiao, Y.H. (2019) Dynamic Pricing of Perishable Products with Hybrid Consumer Buying Behavior. American Journal of Industrial and Business Management, 9, 2263-2272.

https://doi.org/10.4236/ajibm.2019.912150

Received: September 23, 2019

Accepted: December 21, 2019

Published: December 24, 2019

Copyright $\odot 2019$ by author(s) and Scientific Research Publishing Inc. This work is licensed under the Creative Commons Attribution International License (CC BY 4.0).

http://creativecommons.org/licenses/by/4.0/

\begin{abstract}
The acceleration of market information allows consumers to become increasingly "smart". According to current and historical reference price, consumers decide the buying time. Consumer buying behavior brings significant influence to the manufacturers' pricing and revenue. Based on consumer utility function, this article established a two-stage dynamic pricing model and discussed perishable product pricing strategies under consumer behavior and reference price effect. The two-stage optimal pricing and revenue with strategic customer proportion, consumer's valuation decrement and reliance extent of historical price are discussed. We can find that the reservation price decreasing rate declines, consumer behavior affects revenue and pricing more seriously. When the reliance extent increases, the consumers' demand for the product in the second stage increases, the product pricing in the second stage increases. Consumer strategic behavior and reference price effect bring negative effect to manufacturers' revenue.
\end{abstract}

\section{Keywords}

Dynamic Pricing, Perishable Products, Consumer Behavior, Reference Price Effect

\section{Introduction}

With the rapid development of product development technology and the fierce of the market competition, the life cycle of products is becoming shorter and shorter. More and more products have the characteristics of perishable products. Perishable products (also called short life cycle products or seasonal products), have the characteristics: a short sales cycle, large market demand uncertainty and low residual value in the end. These characteristics make manufacturers face difficulties with sales and pricing decision. Current pricing method of perishable 
products which is used widely is dynamic pricing. Because in the entire sales period, consumers' perceived value for product would decline along with the value of product [1]. This leads to manufacturers sell products through some measures such as pricing cutting. According to the changes of the market demand, manufacturers need to carry out dynamic pricing mechanism. In the sales season, manufacturers are increasingly concerned about the influence of consumer behavior on pricing decision.

With the development of Internet, consumers get more and more convenient and comprehensive product information. Consumers are becoming more and more "smart". Combined with current and historical prices of the product, consumers figure out a reserve price according to the current value of a product and buy it when the product price is lower than the reserve price. Besides, the previous price of the product has some effects on the buying behavior of waiting consumers. They decide whether to buy the product on the basis of the selling price and the historical price of perishable products. According to the observation on pricing and discount strategy, consumers have rational expectations of products. Comparing the expected utility of purchasing in different periods, consumers decide the best time to buy. Considering the consumer behavior factors, the optimal dynamic pricing decision for perishable products is getting more and more attention from the manufacturers.

Literature related to this paper is dynamic pricing with consumer's strategic behavior in revenue management and pricing with consumer reference price effect in behavioral economics. Research on dynamic pricing which considers consumer behavior has got scholars' wide concern and research [2]. Aviv and Pazgal assumed that the reserve price decreases with time. Researchers found that if consumers set fixed discount prices in advance, it can make profit increase $8.32 \%$ [3]. Levin et al. studied dynamic pricing of perishable products under consumer's strategic behavior [4]. Linghong Zhang et al. studied perishable products' sales strategies considering dynamic pricing and price reduction point [5]. From the perspective of revenue management, Hainan Li proposed a conceptual model based on strategic consumer buying behavior [6]. Liu et al. established a demand model for perishable products based on two variables: price and quality, and derived the retailer's optimal pricing strategy by maximum principle [7]. Nasiry and Popescu assumed that consumers' reference price is determined by the minimum value between the sales price in the last selling period and historical sales price [8]. Kremer et al. pointed out that when the proportion of strategic passengers is lower than the critical value, the short-term priority strategy is adopted to transfer the strategic consumers to the lag period, and the expected income can be obtained [9]. Bi et al. Researched a two-cycle dynamic pricing model based on hybrid consumers with short-sighted and strategic customers in the competitive environment, but the article didn't give the equilibrium price of the manufacturer [10].

Considering the existence of myopic consumers and strategic consumers in 
the market, this article discusses the dynamic pricing strategy of manufacturer's perishable products from the perspective of consumer behavior, combining with consumer strategic behavior and reference price effect. The research provides reference for the revenue management of enterprises.

\section{Problem Description and Basic Assumptions}

The value of perishable products tends to decay with the passage of time. Such as fruits, vegetables and milk, when approaching the end of the life cycle, the value of the products declines significantly. With the attenuation of the value of perishable products, the reservation price of consumers to the products will also reduce. The change of consumers' reservation price affects the purchase decision. In the face of the decision-making behavior of consumers, manufacturers may have the reduction strategy in the sales cycle. In other words, changes in consumers' reservation price have an impact for manufacturers' pricing decision.

Reference price is one of the standards to measure the price of the products. Consumers will take the past published price of the product as the reference standard to make decisions. The historical price tends to be consumers' reference price and is the consumers' decision-making reference point. Based on the current and historical price of products, consumers form expectations of the products, weigh the utility size and decide the time to buy. In order to describe the reliance extent of historical price, we refer to the mental accounting theory which is put forward by Thaler [11]. The theory points that the consumer utility is composed of purchase utility and transaction utility. The purchase utility is $v-p$, which is the difference between the consumers' valuation of products and the price of the product; the transaction utility is $r-p$, which is the difference between the consumers' reference price of products and the price of the product.

Due to the difficulty of multi-stage dynamic programming solving, this paper studies the dynamic pricing in the two stages. The sales period $[0, T]$ is divided into full price sales period $\left[0, T_{1}\right]$ and discount sales period $\left[T_{1}, T\right]$. Assuming the number of consumers is $N$, consumer only can buy up to one product in the market each time. Consumers' reservation value of products subjects to uniform distribution $v \sim U[0, V]$. The consumers in the market are hybrid, including myopic consumers and strategic consumers. And the strategic customer proportion is $\alpha, 0 \leq \alpha \leq 1$. The consumers valuation decrement rate is $a, 0 \leq a \leq 1$. We assume the initial inventory of the manufacturer is $Y$, the probability of buying the product in the second stage is $\xi$. Prices in two stages are $p_{1}, p_{2}$, demands for the products are $Q_{1}, Q_{2}$, manufacturer revenues are $R_{1}, R_{2}$, revenue in the entire sales period is $R$. To facilitate the calculation, we assume the product unit cost is zero.

\section{Model and Solution}

In the two-stage dynamic pricing, game between manufacturer and consumers is showed in Figure 1. Next, we discuss product demand and revenue in each stage. 


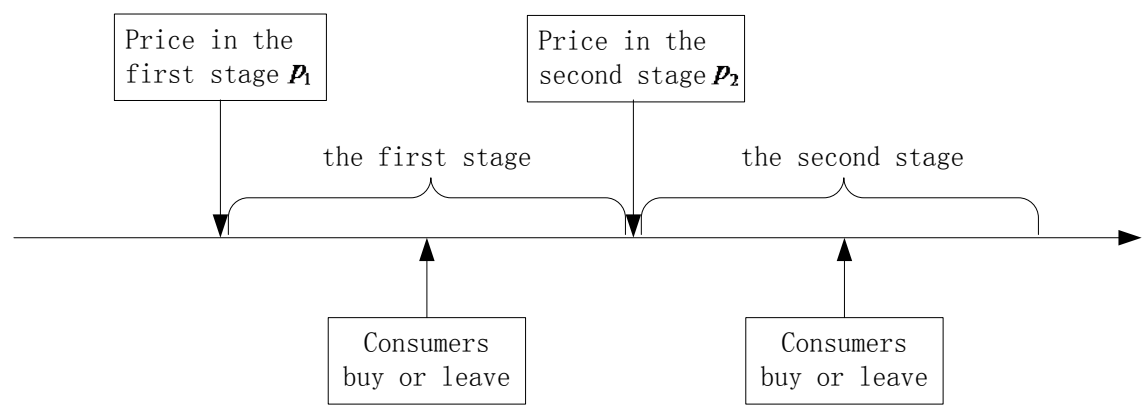

Figure 1. Game between manufacturer and consumers.

Considering the reference effect of consumer purchase decisions, assuming consumers are risk neutral, we define the consumer utility function as:

$$
u(p)=(v-p)+\gamma(r-p),
$$

$(v-p)$ is the difference between the consumer reservation price and the product price, it's direct utility. $\gamma(r-p)$ is reference utility, it's the reference of historic price. $\gamma$ is reliance extent of historical price.

\subsection{Consumer Utility and Demand Functions}

1) $\left[0, T_{1}\right]$ stage

(1) For myopic consumers, the expected utility is $\left(v-p_{1}\right)$. When the expected utility is larger than zero, myopia consumers will buy the product. The critical value of reserve price is $v_{1 m}=p_{1}$. The demand function $Q_{1 m}$ is:

$$
Q_{1 m}=(1-\alpha) N \frac{V-v_{1 m}}{V} \text {. }
$$

(2) For Strategic consumers, they would weigh the utility of two stages. The expected utility is:

$$
\max \left\{\left(v-p_{1}\right),\left\{\xi\left[\left(a v-p_{2}\right)+\gamma\left(r_{2}-p_{2}\right)\right]\right\}\right\} .
$$

The reserve price satisfies: $\left(v-p_{1}\right)=\left\{\xi\left[\left(a v-p_{2}\right)+\gamma\left(r_{2}-p_{2}\right)\right]\right\}$.

When $v_{1 s} \geq \frac{p_{1}-\xi p_{2}+\xi \gamma\left(r_{2}-p_{2}\right)}{1-\xi a}$, strategic consumers decide buying product in the first stage. The demand function $Q_{1 s}$ is:

$$
Q_{1 s}=\alpha N \frac{V-v}{V}=\alpha N \frac{V-v_{1 s}}{V} .
$$

Consumers' perceived price of the second stage mainly relies on the price of the first stage. We assume $r_{2}=p_{1}$, so $v_{1 s}=\frac{p_{1}-\xi p_{2}+\xi \gamma\left(p_{1}-p_{2}\right)}{1-\xi a}$.

Therefore, the total demand function $Q_{1}$ in stage $\left[0, T_{1}\right]$ is:

$$
Q_{1}=(1-\alpha) N \frac{V-v_{1 m}}{V}+\alpha N \frac{V-v_{1 s}}{V}=\frac{N}{V}\left(V-v_{1 m}+\alpha v_{1 m}-\alpha v_{1 s}\right) .
$$

2) $\left[T_{1}, T\right]$ stage

In this stage, when the expected utility is larger than zero, consumers decide 
to buy.

(1) For myopic consumers, consumers decide to buy when the reserve price satisfies: $v-p_{2}+\gamma\left(r_{2}-p_{2}\right)>0$. The demand function $Q_{2 m}$ is:

$$
Q_{2 m}=(1-\alpha) N \frac{v_{1 m}-p_{2}+\gamma\left(r_{2}-p_{2}\right)}{V}=(1-\alpha) N \frac{v_{1 m}-p_{2}+\gamma\left(p_{1}-p_{2}\right)}{V} .
$$

(2) For Strategic consumers, consumers who didn't buy product in the first stage would buy in the second stage if the utility is larger than the price. The demand function $Q_{2 s}$ is:

$$
Q_{2 s}=\alpha N \frac{V-p_{2}+\gamma\left(r_{2}-p_{2}\right)}{V}-\alpha N \frac{V-v_{1 s}}{V}=\alpha N \frac{v_{1 s}-p_{2}+\gamma\left(p_{1}-p_{2}\right)}{V} .
$$

Therefore, the total demand function $Q_{2}$ in stage $\left[T_{1}, T\right]$ is:

$$
\begin{aligned}
Q_{2} & =(1-\alpha) N \frac{v_{1 m}-p_{2}+\gamma\left(p_{1}-p_{2}\right)}{V}+\alpha N \frac{v_{1 s}-p_{2}+\gamma\left(p_{1}-p_{2}\right)}{V} \\
& =\frac{N}{V}\left[(1-\alpha) v_{1 m}+\alpha v_{1 s}-p_{2}+\gamma\left(p_{1}-p_{2}\right)\right]
\end{aligned} .
$$

We define $\frac{V N}{V}=m_{1}, \frac{N}{V}=m_{2}$, putting $v_{1 m}=p_{1}, \quad v_{1 s}=\frac{p_{1}-\xi p_{2}+\xi \gamma\left(p_{1}-p_{2}\right)}{1-\xi a}$ into $Q_{1}, Q_{2}$, we get:

$$
\begin{gathered}
Q_{1}=m_{1}+m_{2}\left[(\alpha-1) p_{1}-\alpha \frac{(1+\xi \gamma) p_{1}-\xi(1+\gamma) p_{2}}{1-\xi a}\right] \\
Q_{2}=m_{2}\left[(1-\alpha+\gamma) p_{1}-(1+\gamma) p_{2}+\alpha \frac{(1+\xi \gamma) p_{1}-\xi(1+\gamma) p_{2}}{1-\xi a}\right] .
\end{gathered}
$$

\subsection{Manufacturer Revenue Function}

According to the above model, we discuss when inventory is adequate.

We put $Q_{1}, Q_{2}$ into revenue function; we can get the total revenue $R$ of the two stages:

$$
\begin{aligned}
R= & p_{1}\left\{m_{1}+m_{2}\left[(\alpha-1) p_{1}-\alpha \frac{(1+\xi \gamma) p_{1}-\xi(1+\gamma) p_{2}}{1-\xi a}\right]\right\} \\
& +p_{2}\left\{m_{2}\left[(1-\alpha+\gamma) p_{1}-(1+\gamma) p_{2}+\alpha \frac{(1+\xi \gamma) p_{1}-\xi(1+\gamma) p_{2}}{1-\xi a}\right]\right\}
\end{aligned}
$$

At this time, the revenue in the second stage is:

$$
R_{2}=p_{2} Q_{2}=p_{2} m_{2}\left[(1-\alpha+\gamma) p_{1}-(1+\gamma) p_{2}+\alpha \frac{(1+\xi \gamma) p_{1}-\xi(1+\gamma) p_{2}}{1-\xi a}\right] \text {. }
$$

We use the reverse solving method. Setting $\frac{\partial R_{2}}{\partial p_{2}}=0$, we can get:

$$
p_{2}^{*}=\frac{(1-\xi a)(1-\alpha+\gamma)+\alpha(1+\xi \gamma)}{2(1+\gamma)(1-\xi a+\alpha \xi)} p_{1}
$$

Putting $p_{2}^{*}$ into $v_{1 s}=\frac{p_{1}-\xi p_{2}+\xi \gamma\left(p_{1}-p_{2}\right)}{1-\xi a}$, we can get: 


$$
v_{1 s}=\frac{(1+\xi \gamma)-\xi(1+\gamma) k}{1-\xi a} p_{1} .
$$

Among them, $k=\frac{(1-\xi a)(1-\alpha+\gamma)+\alpha(1+\xi \gamma)}{2(1+\gamma)(1-\xi a+\alpha \xi)}$.

Putting $p_{2}^{*}=k p_{1}$ into $R$. Setting $\frac{\partial R}{\partial p_{1}}=0$, we can get:

$$
p_{1}^{*}=\frac{(1-\xi a) V}{2(1-\xi a)\left[(1-\alpha)-(1-\alpha+\gamma) k+(1+\gamma) k^{2}\right]+2 \alpha(1-k)[1+\xi \gamma-\xi k(1+\gamma)]} .
$$

Therefore, the manufacturer's optimal price in the first and second stage is:

$$
\begin{gathered}
p_{1}^{*}=\frac{(1-\xi a) V}{2(1-\xi a)\left[(1-\alpha)-(1-\alpha+\gamma) k+(1+\gamma) k^{2}\right]+2 \alpha(1-k)[1+\xi \gamma-\xi k(1+\gamma)]} \\
p_{2}^{*}=\frac{(1-\xi a)(1-\alpha+\gamma)+\alpha(1+\xi \gamma)}{2(1+\gamma)(1-\xi a+\alpha \xi)} p_{1} . \\
\text { Among them, } k=\frac{(1-\xi a)(1-\alpha+\gamma)+\alpha(1+\xi \gamma)}{2(1+\gamma)(1-\xi a+\alpha \xi)} .
\end{gathered}
$$

When the price satisfies above optimal solution, the manufacturer gets the optimal revenue.

\section{Numerical Experiments and Parameter Analysis}

Optimal pricing strategy is given above, according to the changes of the different parameters; we obtain at changes of pricing and revenue in different stages.

1) Analysis of strategic customer proportion $\alpha$

Assuming total number of consumers is 1000; consumer reservation price satisfies uniformly distribution $v \sim U[0, V], V=20$; reliance extent of historical price $\gamma=0.3$; consumers valuation decrement is 0.6 ; the probability of buying products in the second stage is 0.7 ; consumers are risk neutral. Changes of pricing and revenue in different stages are as follows.

Consumers' Strategic behavior leads to consumers are willing to buy product in the second stage. Figure 2 presents effect of strategic customer proportion on revenue. When strategic customer proportion becomes larger, manufacturer chooses to sale products in a discount price. When strategic customer proportion is larger, the negative effect of manufacturer revenue is larger.

2) Analysis of consumer's valuation decrement a

Other assumptions remain unchanged, we assume strategic customer proportion $\alpha$ is 0.6 ; reliance extent of historical price $\gamma=0.3$.

Figure 3 presents effect of consumer's valuation decrement on revenue. The optimal price in the first and second stage is negatively related to consumers' valuation decrement a. Reservation price decreases more slowly, the optimal price becomes smaller.

3) Analysis of reliance extent of historical price $\gamma$

Other assumptions remain unchanged, we assume strategic customer proportion $\alpha$ is 0.6 ; consumers valuation decrement is 0.6 . 


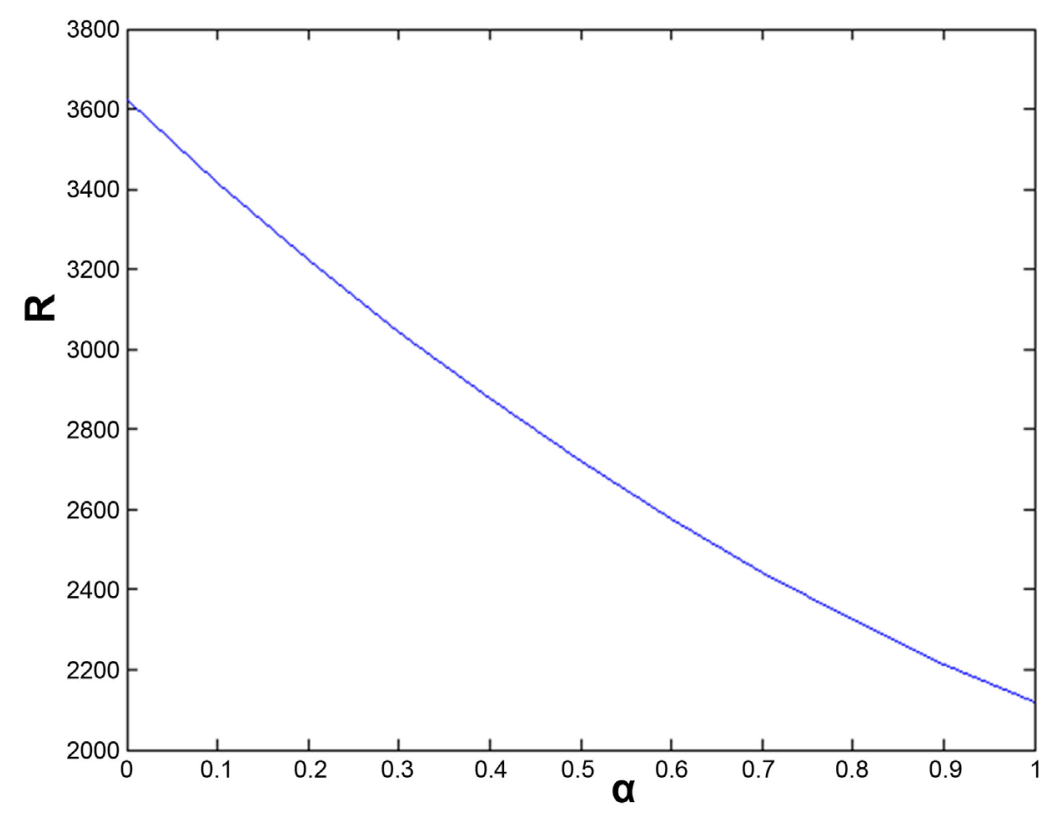

Figure 2. Effect of strategic customer proportion $\alpha$ on revenue $R$.

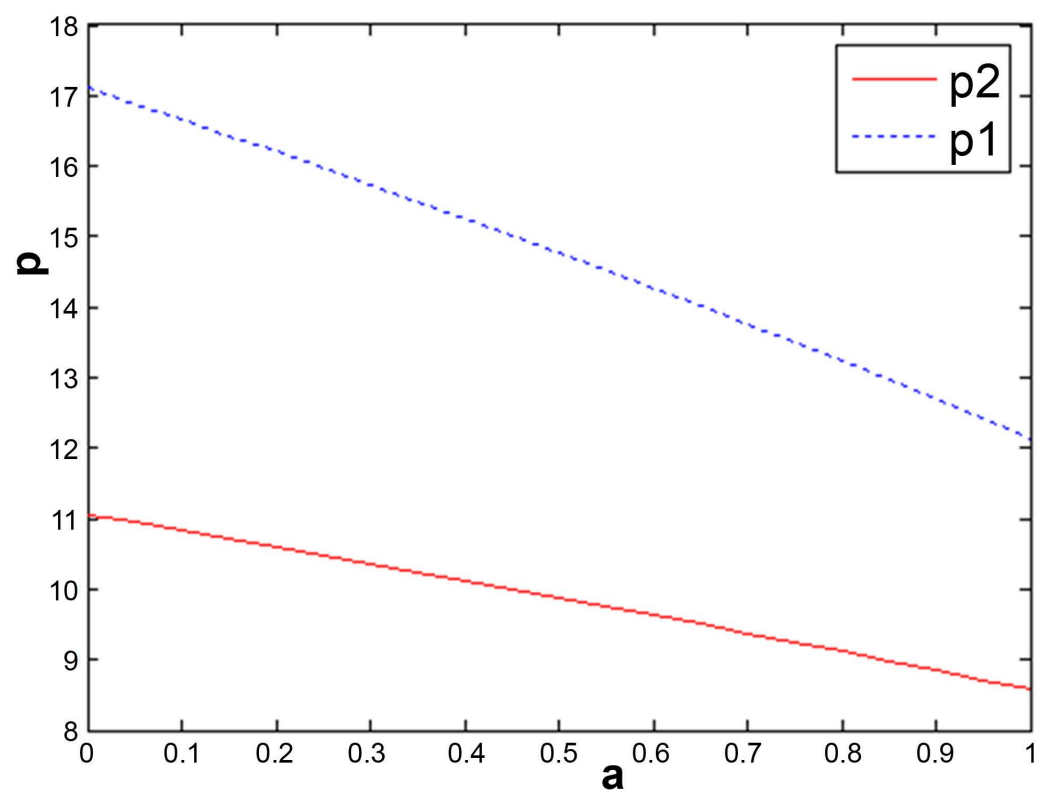

Figure 3. Effect of consumer's valuation decrement $a$ on price $p$.

Figure 4 presents effect of reliance extent of historical price on optimal price. When reliance extent of historical price is larger, consumers would choose to wait and buy product in the second stage. This makes consumers' proceeds feel enhance in the second stage. Consumers' demand for products increases in the second stage and the optimal price in the second stage increases. Besides, price in the second stage also raises the price in the first stage.

4) Analysis of consumer strategic behaviour $\alpha, \xi$

Consumer strategic behavior leads to negative effect of manufacturer's profit. Next, we analyze effect of manufacturer revenue with changes of $\alpha$ and $\xi$. 
Figure 5 shows effect of the probability of buying the product in the second stage $\xi$ on revenue. With the increase of $\xi$, the long-term profit of manufacturer reduces. When the strategic customer proportion is small, manufacturer's profit decline rate is basically unchanged. When the strategic customer proportion is large, manufacturer's profit decline rate increases with the increase of $\xi$.

Figure 6 shows effect of strategic customer proportion $\alpha$ on revenue. When the probability of buying the product in the second stage is small, manufacturer's profit decline rate is basically unchanged. When the probability of buying

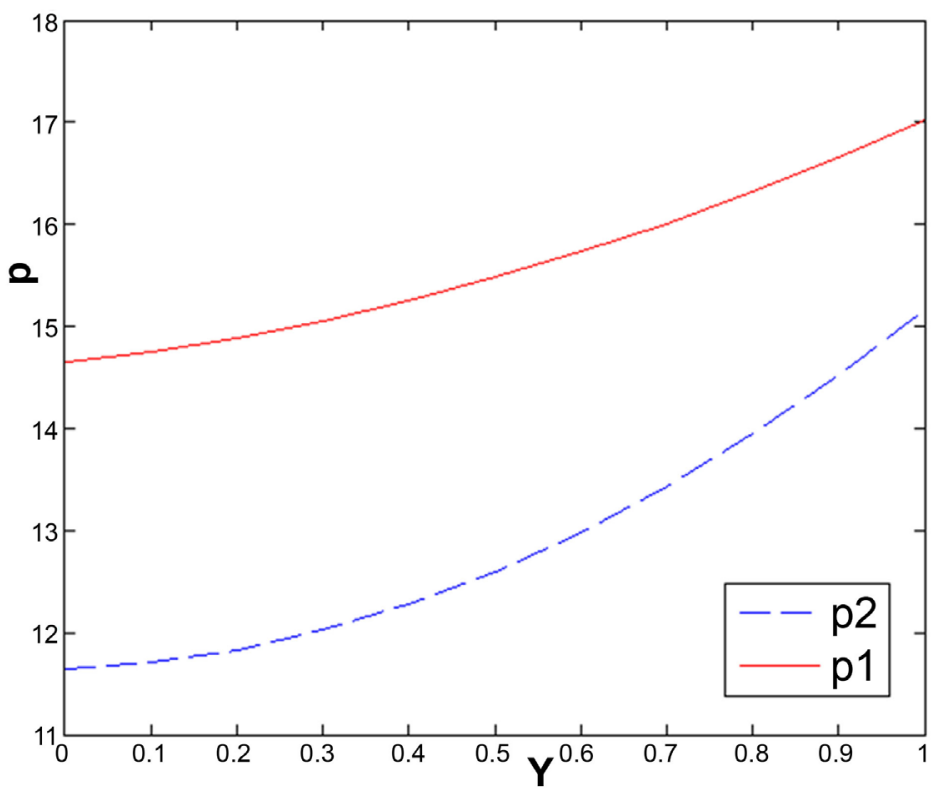

Figure 4. Effect of reliance extent of historical price $\gamma$ on price $p$.

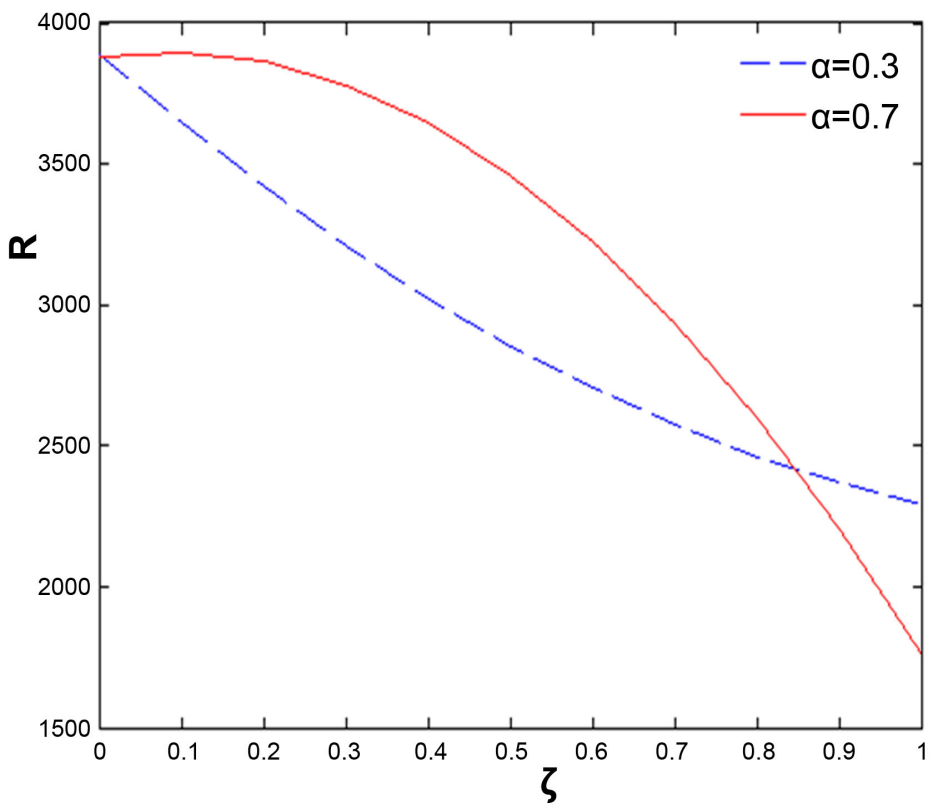

Figure 5. Effect of $\xi$ on revenue $R$. 


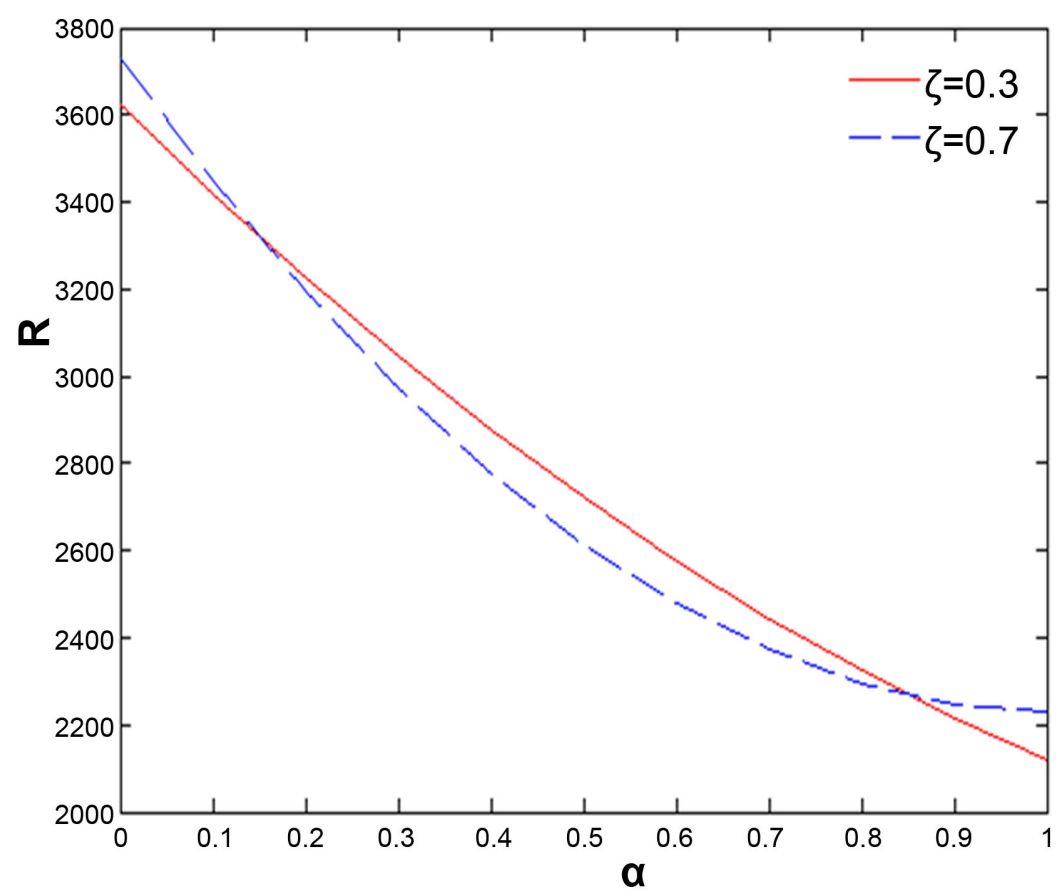

Figure 6. Effect of $\alpha$ on revenue $R$.

the product in the second stage is large, manufacturer's profit decline rate decreases with the increase of $\alpha$.

\section{Conclusions}

With the development of science and technology, we must recognize that consumers' awareness of buying product after weighing the utility of purchase is becoming stronger. The life cycle of product is getting shorter, and the competition among manufacturers is becoming fiercer. Considering consumer strategic behavior and reference price effect, this paper established utility functions, derived demand function and obtained optimal price strategies. The result of research shows that the reserve price decreasing rate declines, consumer behavior affects revenue and pricing more seriously. When the reliance extent increases, the consumers' demand for the product in the second stage increases, the product pricing in the second stage increases.

This article also has many shortcomings. This article only discussed the influence of consumer's strategic behavior and other irrational behavior factors on the manufacturer's revenue, and didn't give the equilibrium price of the two manufacturers. This article only explored two manufacturers, and the game between multiple manufacturers has not been studied. These are the future research contents.

\section{Conflicts of Interest}

The authors declare no conflicts of interest regarding the publication of this paper. 


\section{References}

[1] Cao, H. and Zhou, J. (2004) Studies on the Dynamic Pricing about the Seasonal Product. The Journal of Quantitative \& Technical Economics, 21, 122-125.

[2] Shen, Z.J.M. and Su, X.M. (2007) Customer Behavior Modeling in Revenue Management and Auctions: A Review and New Research Opportunities. Production and Operations Management, 16, 713-728.

https://doi.org/10.1111/j.1937-5956.2007.tb00291.x

[3] Aviv, Y. and Pazgal, A. (2008) Optimal Pricing of Seasonal Products in the Presence of Forward-Looking Consumers. Management Science, 10, 339-359. https://doi.org/10.1287/msom.1070.0183

[4] Levin, Y., McGill, J. and Nediak, M. (2010) Optimal Dynamic Pricing of Perishable Items by a Monopolist Facing Strategic Consumers. Manufacturing \& Service Operations Management, 19, 40-60. https://doi.org/10.1111/j.1937-5956.2009.01046.x

[5] Zhang, L.H., You, J.X. and Chen, Z. (2013) Dynamic Pricing Mechanism of Perishable Product Based on Markdown Timing. Journal of Tongji University (Natural Science), 41, 470-475.

[6] Li, H.N. (2012) Revenue-Management-Based Customer Response Model and Strategic Behavior Analysis. Shanghai Management Science, 34, 15-18.

[7] Liu, G., Zhang, J. and Tang, W. (2015) Joint Dynamic Pricing and Investment Strategy for Perishable Foods with Price-Quality Dependent Demand. Annals of Operations Research, 226, 397-416. https://doi.org/10.1007/s10479-014-1671-x

[8] Nasiry, J. and Popescu, I. (2011) Dynamic Pricing with Loss-Averse Consumers and Peak-End Anchoring. Operations Research-Baltimore, 59, 1361.

https://doi.org/10.1287/opre.1110.0952

[9] Kremer, M., Mantin, B. and Ovchinnikov, A. (2017) Dynamic Pricing in the Presence of Myopic and Strategic Consumers: Theory and Experiment. Production and Operations Management, 26, 116-133. https://doi.org/10.1111/poms.12607

[10] Bi, G., Li, L., Yang, F. and Liang, L. (2014) Dynamic Pricing Based on Strategic Consumers and Substitutes in a Duopoly Setting. Discrete Dynamics in Nature \& Society, 2014, Article ID: 694568. https://doi.org/10.1155/2014/694568

[11] Thaler, R. (1980) Toward a Positive Theory of Consumer Choice. Journal of Economic Behavior \& Organization, 1, 39-60.

https://doi.org/10.1016/0167-2681(80)90051-7 